\title{
A CONTRIBUIÇÃO DA METODOLOGIA QUALITATIVA PARA A ÁREA HOSPITALAR.
}

\author{
Iris Fenner Bertani ${ }^{1}$
}

\begin{abstract}
Resumo
Os pesquisadores das ciências sociais aplicadas, tanto de iniciação científica como mestrandos e doutorandos, têm utilizado a metodologia da pesquisa qualitativa como instrumento preferencial para o desvendamento da realidade do usuário do hospital público. Esta atitude entra em desacordo com a cultura institucional hospitalar tradicional, de percepção e elucidação da realidade por meio do levantamento numérico quantitativo entendido como pensamento racional e científico e única forma de afastar-se do empirismo e da improvisação na área do tratamento e cuidados. Ao desenvolver a postura baseada no raciocínio heurístico-dialético como alternativa incluída no entendimento e explicação do mundo, o pesquisador revela as condições conjunturais e estruturais da sociedade e o seu rebatimento na vida e modo de ver o mundo dos doentes internados. Apresenta uma contribuição importante ao possibilitar maior visibilidade ao fator humano socialmente compreendido, ás relações hospitalares entre o doente e a equipe, e durante o tratamento em si.
\end{abstract}

Palavras-chave: pesquisa; metodologia; saúde; hospital; Serviço Social.

\section{DESENVOLVIMENTO DA COMUNICAÇÃO}

\section{INTRODUÇÃO:}

Durante nosso desempenho profissional como docente no Departamento de Serviço Social da UNESP, Campus de Franca, freqüentemente somos procurados por pesquisadores iniciantes ou mais experimentados, interessados em desenvolver seus projetos na área da saúde com a utilização da metodologia qualitativa. São alunos do curso de graduação em Serviço Social, mestrandos e doutorandos do Programa de Pós Graduação em Serviço Social, profissionais e pesquisadoras envolvidas nos projetos do Grupo de Estudos e Pesquisas sobre Saúde, Qualidade de Vida e Relações de Trabalho - QUAVISSS. Investigam a formação histórica das ações de saúde, as políticas públicas, a educação continuada, movimentos populares, diretrizes constitucionais, iniciativas de participação da população, o controle social, situações e programas e específicos.

\footnotetext{
${ }^{1}$ Departamento de Serviço Social - UNESP - Campus Franca. Grupo de Estudos sobre Saúde, Qualidade de Vida e Relações de Trabalho - QUAVISSS.

Rua Major Claudiano, 1488- Centro - CEP 14400-690. Franca - São Paulo irisfenner@ netsite.com.br
} 
O que se observa atualmente é que o pesquisador das ciências sociais aplicadas ao se dedicar cada vez com maior freqüência ao desenvolvimento de pesquisas na área da saúde, tem concentrado estudos no campo da doença institucionalizada por excelência, os hospitais. Este espaço, se nos anos 1970 era privilegiado pela centralidade da atenção médica, atualmente é disputada como locus preferencial de investigação e desenvolvimento de novos conhecimentos para os demais profissionais, legitimados principalmente pela gestão dos Programas de Qualidade e o discurso da humanização da assistência, regulamentada pelo Ministério da Saúde como Programa Nacional de Humanização da Assistência Hospitalar - PNHAH (BRASIL, 2001).

A produção científica dos pesquisadores das ciências sociais e humanas tem acompanhado pari passu essas mudanças pela própria concepção dominante de saúde desde a Constituição de 1988, voltada a aspectos preventivos integrados ao desenvolvimento da estrutura social, mudando a feição atual das ações dos profissionais da saúde, pela ampliação de parcerias e divisão de responsabilidades. Esta ampliação da compreensão e da abordagem das ações de saúde deslocase do setor curativo, enfatiza o cuidado preventivo, o promocional e o educativo, o que resulta em maiores expectativas e exigências sobre o desempenho do papel profissional dos diferentes membros da equipe. Baseados no entendimento de saúde como "[...] resultado das condições de alimentação, habitação, educação, renda, meio-ambiente, trabalho, transporte, emprego, lazer, acesso e posse da terra e acesso a serviços de saúde Isto, de certa forma, caracteriza mais oportunamente o campo de saberes e práticas dos pesquisadores cujo embasamento profissional enxerga na configuração social de uma dada sociedade, o determinante das condições de saúde de uma população e estágio de desenvolvimento da nação. (BRASIL, 1988).

O hospital, todavia, a despeito de haver consenso na sociedade sobre a importância das ações e práticas preventivas, continua visto pela população como um centro de cuidados de saúde da maior significância. A centralidade dos recursos, a disponibilização de alimentação balanceada e medicação na hora certa, o repouso na doença, só são possíveis para grande parte da população quando internados no hospital. De outro lado, jornais, rádios e TVs mostram continuamente o lado negativo do nível primário e secundário do sistema de saúde do país: filas de espera, situação de descaso e negligência, carência de profissionais, falta crônica de medicamentos e material para curativos, culminando na "consulta relâmpago". O hospital como opção terapêutica tem sido uma constante observada entre a população, desafiando os níveis de racionalização e hierarquização dos atendimentos estabelecidos pelo Sistema Único de Saúde - SUS.

O grande contingente de profissionais da saúde não-médicos que trabalha no hospital hoje expressa essa característica de colocação no mercado de trabalho. Sua atuação junto ao usuário se caracteriza por demonstrar à equipe, em cada situação particular encontrada, que a sociedade e as condições sociais, econômicas, políticas e culturais de vida do usuário e família não ficam do lado de fora da porta do hospital aguardando a intervenção médica. Estão e permanecem no leito, na noite, na dor, na solução e na complexidade das doenças, nos quadros das patogenias, no processo de reabilitação, junto, sempre junto ao doente. As manifestações das condições sociais adversas percebidas no corpo dos usuários, muitas vezes são explicadas como doença, tornandoas racionais, objetivas, concretas e visíveis. É quando se abstrai o sujeito de sua própria doença, identificando-a como um fato patológico, buscando no corpo, a configuração ideal do desenho nosográfico (BRANT; MINAYO-GOMEZ, 2004). Outras dores e sofrimentos residem no 
doente, e podem interferir no processo de tratamento. Estas só podem ser conhecidas por meio do próprio relato do sujeito que sofre, em ambiente de segurança e clima de confiança. Muitos profissionais, para suplantar essas barreiras, se debruçam sobre a possibilidade de criar essa confiabilidade, visando desenvolver o processo de ajuda.

Durante a atuação do aluno, estagiário, aprimorando, pós-graduando e profissional em hospitais, ao atender regularmente os usuários internados de ambos os sexos, adultos e crianças, portadores das diversas manifestações de doenças instaladas, e nos contatos com seus familiares, bem como ao participar da equipe interprofissional, que são realizados os levantamentos qualitativos e suas reflexões possíveis.

\section{DESENVOLVIMENTO DO CONTEÚDO:}

O doente e seus familiares constituem o universo de trabalho no setor terciário de atenção à saúde, constituído pelos hospitais públicos, de acordo com a regulamentação do SUS. Cabe ao pesquisador identificar a configuração social dos usuários internados e suas relações familiares, culturais, trazendo sua contribuição para o quadro de compreensão da vida do doente, além da especialidade clínica e tipo de patologia, diferenças de gênero, idade e estágios da doença. Explicar o que corre lado a lado aos fatores biológicos no desencadeamento da doença torna-se, portanto uma contribuição a ser realizada, pautada em trâmites científicos. Há, para isso, o cuidado na escolha da metodologia que permita ao pesquisador social colaborar com as medidas terapêuticas, na complementação das informações sobre a vida e o cotidiano do usuário, apresentando dados contextualizados sobre a questão social e a doença.

Definida a temática de interesse a partir da observação empírica, a primeira etapa do trabalho para o pesquisador, após o aval da Comissão de Ética em Pesquisa (CEP) tem sido a de caracterizar os sujeitos de forma a localizá-los no mundo real de ação e vida, realizando o "perfil demográfico ou sócio econômico". Efetuada a seleção inicial dos sujeitos a serem entrevistados, são definidos os aspectos circunstanciais dominantes como o estágio da doença, sexo e idade. A seguir, cada sujeito "escolhido" é informado sobre o processo de pesquisa e consultado a respeito de sua concordância na participação deste projeto. Esta é a etapa em que se dá a leitura do Termo de Consentimento Pós-Informado, conforme parâmetros éticos para pesquisa com seres humanos. O Termo é, a seguir, assinado pelo pesquisador, pelo entrevistado e testemunhas.

Desses doentes, e em coerência com a finalidade de cada estudo, são definidos os corpora, sobre os quais se colhe depoimentos sobre o tema determinado. Estes corpora perfazem o total de sujeitos sobre os quais se desenvolverá a investigação, e tem seu limite no esgotamento dos dados, quando a informação colhida naquele universo e sobre o tema definido se tornar de certa forma repetitiva e constante, refletindo uma área de consenso de ponto de vista naquele segmento escolhido como objeto de conhecimento. A limitação da amostra assim realizada causa impacto no universo hospitalar, sendo frequientemente, alvo de incompreensões e recebendo acusações de que a tomada de depoimentos seria apenas um palavrório subjetivo, parcial e não confiável; os dados freqüentemente se apresentando deturpados. (QUEIROZ; 1988 p18); (JORGE; 1997 p.162). 
A esta proposição, dita racional, podemos acrescentar que as percepções humanas não são monolíticas e que a experiência de vida pode ser configurada como uma encruzilhada entre o subjetivo e o objetivo, ou seja, entre gostos, valores, sonhos, herança biológica, camada social e estruturas sociais. Neste momento, essas manifestações deixam de ser subjetivas e entram para o domínio dos acontecimentos da vida, passíveis de análise.

Na pesquisa qualitativa, como recomenda Minayo (1988, p.363), considera-se a identificação das condições sociais relacionadas ao desencadeamento da doença como "informação básica necessária para a compreensão do universo social dos doentes e do sistema de saúde". O que é inovador nesta visão é que se abandona a sintomatologia clínica como único indicador de doença, mesmo o usuário estando internado por queixas identificadas no corpo e/ou mente, causando tanto desconforto que necessita ficar acamado, recolhido, tratado.

Os depoimentos são colhidos com a utilização de técnica de entrevista não estruturada, orientada pela intencionalidade pré-estabelecida, contando com certo encaminhamento temático direcionado a enfocar o discurso e o comportamento a ser analisado. Dá-se vida, aos poucos, ao roteiro, e as questões vão-se revelando a partir da própria dinâmica das entrevistas. Esse roteiro é constituído de pontos, tópicos a serem lembrados "apenas para não esquecer de tocar em algum aspecto do assunto", considerando que o pesquisador pode ficar envolvido com o relato do usuário do hospital sobre algum aspecto específico que lhe tocou mais profundamente durante a vivência da doença.

Muitas vezes, o pesquisador iniciante, preocupado em acumular informações, não espera novas contribuições espontâneas do entrevistado, e imediatamente faz a segunda, terceira pergunta, e assim sucessivamente, na ânsia de não esquecer o que deve ser levantado sobre a temática que está explorando. Fica mais preocupado em fazer "a lição de casa", deixando de usufruir todas as possibilidades que podem proporcionar o processo de pesquisa e o contato com as revelações do entrevistado.

O método qualitativo, ao proporcionar a identificação da lógica interna do entrevistado, considera-se que esta explicação não vem pronta, mas vai sendo estruturada a partir de relatos realizados pelos sujeitos da pesquisa sobre sua concepção de vida, doença e de hospital. A escolha do instrumento de coleta de dados, a entrevista baseada em roteiro semi-estruturado, justifica-se pelo próprio objeto de estudo.

O que nestes casos busca-se conhecer, não se dirige ao estudo de tendências epidemiológicas de grandes populações, mas como este estado de coisas se reflete e se consolida no cotidiano das pessoas comuns. Não há, como se observa, a preocupação com a obtenção de grandes números que, pela repetição de uma dada circunstância e, após uma análise probabilística, levem à predição de novos acontecimentos. Trata-se de um outro nível de abordagem, que busca significados, motivos, aspirações, atitudes, crenças e valores que dão a cada doente o ensejo de permanecer lutando por sua sobrevivência, ainda que diante de condições adversas. É quando se indaga o que há de comum entre doentes e doenças, deixando o doente falar de forma livre, mas indutiva sobre como percebe um determinado aspecto do real rebatendo em seu universo pessoal, socialmente determinado. 
Mas, ainda que pareça estranho após o reconhecimento da sociedade em geral das vantagens possibilitadas pela aplicação dos resultados obtidos pelas pesquisas quantitativas, não é esse o objeto de interesse da metodologia que ora discutimos. Procuramos aqui, conhecer a compreensão do significado da doença para um determinado grupo de pessoas recebendo tratamento para sua doença no setor terciário de atendimento à saúde, separados por tipo de especialização clínica e que necessitam de recursos sofisticados e alta tecnologia. Os doentes que dependem da complexidade dos recursos do hospital para continuarem vivos.

O artigo de Minayo e Sanches (1993; p 245) orienta essa busca para a fala cotidiana, na revelação coloquial das tramas das relações sociais e condições estruturais, de valores, normas e símbolos transmitindo "representações de grupos determinados em condições históricas, sócio-econômicas e culturais específicas".

A concepção e elaboração da doença na vida das pessoas as levam a uma dupla organização de sua representação, uma no plano cognitivo, outra no plano simbólico: o que as pessoas sabem e pensam; o que sentem, interpretam e dão sentido. Outro aspecto desta questão deve aqui ser considerado, pois ao se deter no que as pessoas pensam e sentem sobre a doença, não há uma teorização voltada apenas à subjetividade e às emoções, mas a esse conjunto de condições pessoais e únicos, mediados e compreendidos dialeticamente pela interação com a sociedade capitalista atual e o humano global.

A abordagem qualitativa, uma vez realizada, e obtida a informação desejada, requer uma imersão no conteúdo e significado dos depoimentos, de forma a compreendê-los e explicá-los de acordo com um quadro de referência sócio-histórico.

As questões relativas à vida e ao modo de ver-o-mundo, a submissão ("paciência-paciente") a essa nova experiência de vida, "desvela-se com a força daquele que viveu, para aquele que sabe", utilizando a expressão cunhada por Ferreira e Ammado (1996, p 37), que declaram ainda: "a história pertence, sobretudo, àqueles que a viveram”. (FERREIRA E AMMADO, 1996, p.98).

Pela sua natureza, as entrevistas devem ser realizadas em local reservado, que garanta a facilidade de ambientação entre pesquisador e sujeito pesquisado nos serviços de saúde. Ao se criar uma relação de confiança, estabelecido um vínculo de empatia, busca-se superar resistências em relatar, talvez algum receio de julgamentos e avaliações depreciativas ou até punitivas. É possível que este temor esteja ou não presente no depoimento, conforme o universo de referência do entrevistado e a percepção sentida do clima institucional hospitalar, onde os profissionais muitas vezes se vêem e/ou são vistos como detentores do poder "do saber e da cura". Medidas terapêuticas não completamente compreendidas podem (ou não) ser rigorosamente seguidas, por não encontrarem rebatimento nas tradições culturais internalizadas dos doentes. As histórias de desagradáveis experiências anteriores de pequenas desobediências aos ditames de profissionais da equipe de tratamento e de cuidados, não são estranhas à maioria dos usuários de hospitais públicos. Podem criar situações de sofrimento e de dor e até fantasias de descaso, dependendo da situação e do comprometimento emocional dos atores envolvidos. 
Direciona-se, assim, o estudo como resposta às indagações que centralizam o objeto de trabalho, enfocando quais as situações, que do ponto de vista dos doentes, podem ser atribuídas como fatores relacionados / desencadeadores / mantenedores da doença. Os doentes são então convidados a falarem sobre como pensam e convivem com a doença.

A forma de pensar, de agir e de se expressar define a visão de mundo de uma população em termos gerais, mas, sobretudo por se tratar de uma questão vital, a relação de continuidade entre o que diz respeito à saúde-doença-saúde, pode ser destacada dentre as demais, como expressão crucial das representações sociais. A explicação buscada pelo pesquisador, apesar de sua importância na vida das pessoas, não se encontra pronta, racionalmente elaborada, dependendo apenas de indagação para ser revelada.

A maneira de ver-viver a doença pode levar o sujeito a orientar suas condutas, embora não haja qualquer relação direta, preditiva. É esse o encanto humano: Herzelich (1991, p 27) lembra que não pode haver ligação mecânica entre uma representação coletiva e uma conduta individual específica. As visões do biológico e do social são inter-relacionadas, mas esse conjunto ultrapassa qualquer das duas partes.

No encaminhamento do estudo qualitativo, após o trabalho de campo, o material passa a receber um tratamento específico totalmente diferente do usado para inferências estatísticas. Todo o conjunto das entrevistas é trabalhado, passando por uma ordenação e categorização, na tentativa de estabelecer uma compreensão do sentido das palavras (hermenêutica) e o desvendamento da "lógica interna" indicada pelas estruturas de relevância do grupo em estudo. Em seguida, processa-se a análise contextual, articulando-se a hermenêutica à dialética, buscando entender os componentes de especificidade histórica e de diferenciações internas do conjunto dos entrevistados; e das articulações e divergências entre o senso comum e a vivência da doença com o saber e a prática médica.

\section{CONSIDERAÇÕES FINAIS:}

A elaboração das significações, socialmente codificadas pela mediação da palavra, é apresentada no discurso dos sujeitos entrevistados. De acordo com Tunes e Simão (1998), esse discurso permite um conhecimento sobre acontecimentos de natureza privada, aos quais somente o sujeito tem acesso. Os relatos passam a ser considerados dados científicos por permitirem inferir, como base de análise elaborada de modo sistemático, em classes de ações ou categorias de análise que possibilita organizar o conhecimento à medida que vai sendo desvendado na parceria pesquisador - pesquisado. Essa base vai sendo construída pelo entrevistado ao atribuir diferentes significados à história vivenciada de sua doença e reinterpretada pelo pesquisador através da construção que leva em conta as categorias empíricas originadas por esses sujeitos.

Não há como negar que a vivência internalizada faz parte da conduta geral do homem, uma dependendo da outra, desfazendo-se a dicotomia objetivo-subjetivo. É quando, na observação de Queiroz (1988, p 40), se dá o ponto de intersecção das relações entre o que é exterior ao sujeito e o que ele traz em seu íntimo. Buscar conhecer uma impressão, opinião, vivência, modo de ver o mundo, sem permitir a livre expressão dirigida do interlocutor, é o mesmo que se fechar dentro 
de um círculo estreito, partindo da opinião científica do pesquisador sobre situações subjetivas que a outro pertencem.

De Goldmann (1976, p 204) emprestamos a afirmativa da "constante busca pelo equilíbrio entre estruturas mentais do sujeito e o mundo exterior", levando-o a se transformar enquanto transforma o mundo, o que o leva a novo equilíbrio. É a distribuição das estruturações anteriores e a busca de novos equilíbrios dentro da complexa rede de relações interindividuais a que as pessoas pertencem na sociedade e que agem sobre a consciência individual.

Esta função simultaneamente individual e coletiva apresenta caracteres estruturados entre um sujeito e o meio ambiente. Goldmann (1976, p 219) chega à afirmação de um "ponto de encontro das formas da consciência coletiva e a coerência da consciência individual.".

Cada passo adiante na coleta de informações volta a direcionar o prosseguimento da pesquisa, levando o pesquisador a reflexões, orientado pelo seu objetivo de estudo gradualmente construído junto com o sujeito. Estas idas e vindas do pesquisador para conhecer a informação do sujeito não se efetuam para conferir a sua veracidade, mas esclarecer algum aspecto não totalmente compreendido pelo pesquisador em reflexões posteriores, de forma a garantir a confiabilidade, como orienta Demo (1985). Aos poucos, a lógica dos significados se impõe e vai desenhando a "versão da realidade demonstrada como relevante, no contexto dado, possibilitando uma análise objetiva dos fenômenos conscientes". (Tunes e Simão; 1998 p11).

Ao enfocar a doença, o status do órgão doente no imaginário social, a percepção da vida e da morte, a visão de mundo e outras questões humanas fundamentais, torna-se clara a percepção do ponto de intersecção referido por Queiroz (1988) ou o ponto de encontro, como quer Goldmann (1976) entre as representações internas e o mundo externo.

O pesquisador voltado à análise sócio-histórica de seu objeto de estudos, estabelece algumas précategorias de análise com base em reflexões empíricas e bibliográficas. Detém-se na análise dos sentimentos que vão desde a vergonha de ser doente e improdutivo em nossa sociedade que valoriza o grande consumidor como "vencedor". Busca desvendar as estratégias de preservação da auto-estima; a raiva da dor persistente e a esperança de melhorar, de ficar saudável de novo. Identifica ainda o apoio que o doente encontra nas relações familiares e na amizade até seu contrário, o sentir-se um peso a ser descartado. Considera a sustentação e a proteção encontradas na espiritualidade, e sua contrapartida, a manipulação da religião como conjunto de normas e conseqüente alienação. Demonstra a manifestação da doença e suas fronteiras com as relações sociais, revelando as contradições da questão social nas vidas cotidianas particulares. Enfoca a vida que os doentes desejavam ter vivido e aquela que realmente vivem, e as elaborações que realizam para conciliar sonhos com realidade, possibilidades e limites.

Ao pesquisador, esta ferramenta sistemática e consistente de abrir o mundo e ver o humano, nas mediações com o total, possibilita maior visibilidade de seu trabalho, além de embasar cientificamente suas contribuições às ações terapêuticas da equipe hospitalar de tratamento e cuidados. 
Concluindo seu trabalho, o pesquisador elabora o relatório, que entre suas finalidades, além de ser um trabalho para a Academia, deve encaminhar seus produtos para o cotidiano do atendimento de doentes e servir de contribuição às práticas de educação continuada de profissionais da área. Este relatório final usualmente utiliza-se de falas pontuais dos sujeitos pesquisados, localizadas em determinado momento histórico e contextualizadas a partir do conhecimento particular por meio da mediação com a totalidade e universalidade. Ao criar um novo conhecimento da doença, seu impacto e conseqüências ao humano genérico naquilo que nos identificam como parceiros de um mesmo gênero sobre a superfície da terra, hoje, aqui, agora podem surgir novas possibilidades de intervenção e conforto aos doentes.

\section{REFERÊNCIAS BIBLIOGRÁFICAS}

Brasil (1988): CONSTITUIÇÃO. República Federativa do Brasil. Brasília: Senado Federal, Centro Gráfico.

Brasil.(2001). Ministério da Saúde. Secretaria de Assistência à Saúde. PNHAH. Portaria $n^{\circ} 2^{\circ} 2$ de junho de 2001. D.O. 119-E, de 21/06/2001.

Brant; LC; Minayo-Gomez, C. (2004). A transformação do sofrimento em adoecimento: do nascimento da clínica à psicodinâmica do trabalho. Ciência \& Saúde Coletiva. V. 9 (n.1)

Demo, P. (1985) Introdução à Metodologia da Ciência. São Paulo: Atlas, 1985.

Ferreira, M.M; Ammado, J. (Orgs). História oral e tempo presente. São Paulo: Xamã, 1996.

Goldmann, L. A sociologia do romance. Rio de Janeiro: Paz e Terra, 1976.

Herzelich, C. (1991). A problemática da representação social e sua utilidade no campo da doença. PHYSIS .Rev. Saúde Col. Vol1 (2) 24-36.

Jorge, MRT. (1997) A pesquisa qualitativa: premissas, possibilidades e posturas. Serviço Social e Realidade (Franca), v.6, n.2, p.159-172..

Minayo, MCS (1988). Saúde e doença: uma concepção popular da etiologia Cadernos de Saúde Pública. Rio de Janeiro, v. 4, (4), 368-81.

Minayo, MCS.; Sanches, O. (1993) Quantitativo-qualitativo: oposição ou complementaridade. Cad. Saúde Públ. Rio de Janeiro, v.9, (3), 239-62.

Queiroz, MIP. (1988). Relatos orais: do "indizível" ao "dizível". In: Simon, OM Von (org) Experimentos com histórias de vida. São Paulo: Vértice.

QOL Concepts (2002, julho). The quality of life profile: a genetic measure of health and wellbeing. University of Toronto. Disponível em http://www.utoronto.ca/qol ( consulta 2002, 13 jun). 
Tunes, E.; Simão, LM. Sobre a análise do relato verbal. Psicol. USP v.9 n.1 São Paulo: 1998. 